Gerión. Revista de Historia Antigua

ISSN: 0213-0181

http://dx.doi.org/10.5209/GERI.56954

\title{
La paz como victoria en la guerra: el culto a Nike en Atenas del s. V a.C. ${ }^{1}$
}

\author{
Miriam A. Valdés Guía ${ }^{2}$
}

Recibido: 17 de noviembre de 2016 / Aceptado: 14 de mayo de 2017

Resumen. En este artículo analizamos el culto a Nike en Atenas del s. V a.C. en relación con la guerra y específicamente con la paz como reivindicación de la victoria en los conflictos bélicos. Recorremos el culto a Nike desde inicios de siglo, pero nos adentraremos especialmente en la polémica del proyecto arquitectónico del templo de Nike en relación con la famosa Paz de Calias (449) y con la institución del sacerdocio democrático de Atenea Nike que recayó en Mirrina. En la década de los 40 se elabora la paz como victoria, tema que pervive durante la guerra del Peloponeso, como se ve en escritos de esa época como Lisístrata de Aristófanes. Las elaboraciones míticas y cultuales de la guerra y de la paz ponen de relieve el papel que otorgan los griegos a la paz como afirmación de la victoria.

Palabras clave: Nike; Eirene; Paz de Calias; Mirrina.

\section{[en] Peace as Victory in War: the Cult of Nike in Fifth Century Athens}

\begin{abstract}
In this article we analyze the cult of Nike in Athens in fifth century BC in relation to war and specifically to peace as a claim to victory in warlike conflicts. We review the cult of Nike since the beginning of the century but, we will especially address into the controversy of the architectural project of the Nike temple in connection with the famous peace of Callias (449) and with the institution of the democratic priesthood of Athena Nike held by Myrrhine. During the decade of 440, peace was created as a victory, a theme that survived during the Peloponnesian War as we see in documents of that time, such as Aristophanes' Lysistrata. The mythical and cultic elaborations of war and peace highlight the role that Greeks grant the peace as affirmation of victory.
\end{abstract}

Keywords: Nike; Eirene; Peace of Callias; Myrrhine.

Sumario. 1. Introducción. 2. El templo de Atenea Nike. 3. La paz como victoria. 4. Conclusiones. 5. Referencias bibliográficas.

Cómo citar: Valdés Guía, M. (2017) La paz como victoria en la guerra: el culto a Nike en Atenas del s. V a.C., en Gerión 35/1, 39-54.

\footnotetext{
1 Este artículo se ha realizado en el marco del Proyecto de investigación HAR2015-65456-P: La construcción socio-cultural del conflicto: procesos y dinámicas de interacción y enfrentamiento en la Grecia arcaica y clásica.

2 Universidad Complutense de Madrid

E-mail: mavaldes@ucm.es
} 


\section{Introducción}

El primer testimonio de culto a Atenea Nike en Atenas es un altar inscrito dedicado a la diosa en el segundo cuarto del s. VI a.C. ${ }^{3}$ por Patrocles o Patroclides, ${ }^{4}$ aunque hay restos (figurillas, cerámica y algunos huesos de animales pequeños) que permiten conjeturar la existencia de un culto en el bastión desde, al menos, inicios del s. VII. ${ }^{5}$ Ese culto, como hemos argumentado en otro lugar, podría ligarse con Afrodita protectora del matrimonio y de la guerra, como la Nikephoros argiva, cuyo santuario se remonta también al arcaísmo. ${ }^{6}$

Sea como fuere, este espacio se dedica en el s. VI unilateralmente a Atenea con el epíteto Nike, aunque quizás recoge algunas características y tal vez la estatua -que llevaba el casco en una mano y una granada en la otra ${ }^{7}$ del culto más arcaico. $\mathrm{Si}$, como hemos supuesto, este lugar estuvo dedicado a Afrodita portadora de victoria en la guerra y en el matrimonio en el s. VII, se explica el hecho de que permanezcan una serie de resonancias vinculadas a la diosa del amor en este espacio, a cuyos pies, además, se rendía culto a Afrodita Pandemos y Peitho. ${ }^{8}$

En Atenas arcaica, en el segundo cuarto del s. VI, la inauguración del culto de Atenea Nike se asocia, sin duda, con la reorganización de las Panateneas en el 566 y la victoria de la diosa contra los gigantes, motivo propio de la fiesta pentetérica, como hemos desarrollado en otro lugar. El culto podría ligarse asimismo a la reivindicación de la victoria por parte de una u otra facción en la stasis característica de ese siglo. ${ }^{9}$

\section{El templo de Atenea Nike}

$N i k e^{10}$ en la acrópolis está especialmente vinculada con la victoria militar ${ }^{11} \mathrm{y}$ tiene un protagonismo especial, sin duda, en el momento de las guerras médicas, del mismo modo que la tuvo, en esa coyuntura, Afrodita Urania de la acrópolis de Corinto,

3 En adelante, se entenderá que todas las referencias cronológicas son a.C.

4 En torno al 560: $I G \mathrm{I}^{3}$ 596. RAubitscheK 1949, $\mathrm{n}^{\circ} 329$ (nombre Patrocles enmendado por Patroclides: p. 359). MARK (1993, 32-33 y 125) lo fecha entre el 580 y el 560. Giraud 1994, 32.

5 Ver, con bibliografía precedente sobre el tema: Travlos 1971, 148, fig. 201; KüPPER 1989, 21; MARK 1993, 32, n. 7 (baja la cronología de las figurillas); PARKer 1996, 18, n. 33. GEorgaKas 2014, 75. Probablemente, sin embargo, de la primera mitad del s. VII como señala PARISI 2014, 27-29.

6 Cree que antes de Atenea Nike hay una divinidad femenina que custodia el bastión ya desde época micénica: SimON 1985, 271-272. Hipótesis de un culto de Afrodita allí desde época alto arcaica: VALDÉs 2005, 104-113. Afrodita Nikephoros de Argos: Paus. 2.1.6. Restos de armas en el santuario desde el s. VII: MARCHETTI 1993; ID. 1994. En su vertiente matrimonial: PIRENNE-Delforge 1994, 153.

7 Heliodoro en Harp. s.v. Nike Athena; MARK 1993, 93 y ss.; Simon 1985, 272, quien señala que Atenea Nike conservaría los símbolos de la divinidad femenina precedente. RIDGWAY 1992, 135; GIRAUD 1994, 28-29. Cf. Paus. $1.22 .4 ; 3.15 .7$ y 5.26.6.

8 Cf. Beschi 1967-1968.

9 VAldÉs e.p. 2. Reorganización de Panateneas pentetéricas y vínculo con Nike: RAUBITSCHEK 1949, 359; PARKER 1996, 90; SHEAR 2001, 31 y ss. Para personificación de conceptos abstractos cf. SMITH 2011, 20 (Nike).

10 Para Nike en general puede verse: Lonis 1979, 234-238. Iconografía: GoulAKI-VoutiRA - MouSTAKA - GROTE 1992.

11 Aunque sin descuidar la victoria en deportes: PARKer 1996, 90; ID. 2005, 398-399. Guerra: BLOK 2014, 104 (con bibliografía). Nike en vasos que escenifican los premios concedidos en los juegos en Polígnoto: MATHESON 1995, 206-207. 
vinculada a la victoria en la guerra y en los juegos. ${ }^{12}$ El recurso a Nike en Atenas en las guerras médicas se constata en la ofrenda y en la oración de Temístocles dirigida curiosamente "A Atenea y a Nike". ${ }^{13}$ De ese periodo es la dedicación de una probable Nike por parte de Calímaco, polemarco del 490, que testimonia, por una parte, su victoria en los juegos olímpicos, y por otra, su papel en la batalla de Maratón. ${ }^{14}$ Nike está también implicada en la victoria de Salamina. ${ }^{15}$ Es posible que en esas fechas los vasos áticos, además de representar Nikai aladas, aludan específicamente a la diosa "Atenea Nike" en imágenes de la diosa con el casco, a veces corintio, en la mano y con el pelo suelto. ${ }^{16}$

Probablemente después de las guerras médicas, en el momento de apogeo de Cimón, se construyó en el bastión un naiskos junto al altar de Atenea Nike para albergar la estatua de la diosa victoriosa. ${ }^{17}$

En cualquier caso la gran polémica sobre la construcción del templo conocido de Atenea Nike, iniciado en la década de los 20 del s. V, gira en torno a la fecha en la que se planificó. Según la versión más extendida ${ }^{18}$ se proyectó en las primeras fases del inicio de las edificaciones acropolitanas, es decir, a inicios de los años 40, coincidiendo precisamente con la "Paz de Calias", acuerdo largamente discutido en la historiografía, ${ }^{19}$ pero que supuso, sin duda, el cese de las hostilidades frente a los

12 Ath. 13.573c-e; Plu. Moralia 871a-b; sch. Pi. O. 13.32b. Fiesta de Afrodisias: Ath. 13.574b (Alex. Fr. 255Kassel-Austin). Acción de gracias de Jenofonte de Corinto por su victoria en juegos olímpicos: Pi. Fr. 122 Snell-Maehler; Ath. 13.573 e-f y 13.574a; Pirenne-Delforge 1994, 106-113.

13 Hdt. 8.77. Meiggs-Lewis 1988, 39, 23. Lonis 1979, 242 (quien señala el culto de Nike independiente de Atenea). Para ofrendas de victoria en la acrópolis desde época arcaica y clásica: cf. HuRwIT 1999, 230-231 (victorias de oro: ver nota 24). Solo hay una Nike de mármol de época arcaica en la acrópolis: KeESLING 2003, 144. Para evidencia iconográfica: GoulaKi-Voutira - MoustakA - Grote 1992.

14 Raubitschek 1940. Meigss-Lewis 1988, 32, nº 18 (34) = IG I² 609. Osborne-Byrne 1994, 249. Polemarco Calímaco: Hdt. 6.109-110. Ver también: Hurwit 1999, 130; Holtzmann 2003, 68-69.

15 Hdt. 8.77; LONIS 1979, 232.

16 Para representaciones de Nikai aladas de este periodo en los vasos: GoulaKi-Voutira - MoustaKA - Grote 1992, 852-857 (arcaicas), 857-881 (clásicas). En varias imágenes de vasos atenienses de principios del s. V se caracteriza a Atenea con el casco corintio; en ellos aparece por un lado la diosa completamente armada con casco ático como Promachos y por el otro lado la diosa en una imagen que resalta más su belleza y su gracia con el casco corintio en una mano y con el cabello suelto; no hay que olvidar que Atenea Nike era representada aptera en su xoanon arcaico y con el casco en la mano (ver nota 7): cf. RiTTER 2001, 161; DEMARGNE 1984, $1010, n^{\circ}$ 582. La gracia y belleza de la diosa en este caso, como en el de otro vaso en el que se marcan claramente los atributos femeninos de la diosa (los pechos) a través de la tela, apareciendo como una Afrodita y portando el casco corintio en una mano y la espada en la otra (Met. Museum 09.221.43; Beazley archive: www. beazley.ox.ac.uk/record/73D2AE6E-AD97-4D3F-9534-4A56121404EB), pueden remitir al vínculo del bastión señalado más arriba con Afrodita (ver VALDÉs 2005, 81 y 89-90: en Corinto, Afrodita parece que se representa con casco corintio también). En una hydria del 500-480 se muestra a la diosa Atenea sentada en un taburete con el casco en la mano izquierda y un phiale en la mano derecha: Demargne 1984, 1010, $\mathrm{n}^{\circ}$ 580. Varios de los vasos que representan a Nike lo hacen con el phiale en la mano también. Estos vasos podrían, de algún modo, hacer alusión a Atenea Nike en un contexto ateniense en el que se resalta la victoria contra los persas (Maratón y Salamina).

17 Ver infra nota 29.

18 Papademetriou 1948-1949, 146-153; Wade-Gery 1958, 209; Merit - Wade-Gery 1963, 100 y ss.; MeiggsLEWIS 1988, 44.

19 Escepticismo sobre la existencia de una paz formal a partir del análisis de las distintas tradiciones: SCHRADER 1976. El problema con esta paz es que no es citada por fuentes del s. V (PLÁcido 1999, 327-333), sólo a partir del s. IV. Posiblemente se puso especialmente de relieve en el momento de la Paz de Timoteo (ver más abajo en texto). Teopompo duda, incluso, de la existencia de la paz: FGH 115, F 153-154; en este sentido: MeISTER 1982; más bibliografía en BADIAN 1987, 1-39, y PODLECKI 1998, 67, n. 46. Algunas fuentes antiguas la sitúan de forma clara en el 449, Diodoro Sículo (12.4.4), Aristodemo (FGH 104 F 13) y la Suda (s.v. Kallias). Otras (P1. Mx. 241d-f-242a; Lycurg. Leocrates, 72-3, Plu. Cim. 12-13, que reproduce un fragmento de Calístenes $-F G H$ 
persas. En esa conyuntura la $\mathrm{paz}^{20} \mathrm{o}$ pacto se pretende construir, en momentos en los que Atenas tiene dificultades dentro de la liga de Delos por el desastre de la expedición a Egipto y por la guerra con Esparta, como una victoria contra los persas, rememorando, sin duda, las guerras médicas, ocasión en la que se había prestado atención especial a Nike. Desde mediados del s. V se renuevan con profusión las representaciones en la cerámica de la victoria contra las amazonas por parte de Teseo, tema que se elabora en el imaginario griego en relación con los bárbaros y específicamente con los persas, ${ }^{21}$ recordando de este modo las guerras médicas.

La Paz de Calias es una paz "victoriosa", igual que en el siglo IV la paz de Timoteo ${ }^{22}$ descrita por Plácido como una paz "imperialista". ${ }^{23}$ El acuerdo del 375 coincide con la inauguración de un culto regular a Eirene. En esos momento se evoca y se "retorna" al pasado y se "construye", como referente, la paz victoriosa de Calias. Ésta había sido realizada en el contexto imperialista de la Atenas de Pericles, en una década en la que convenía afirmar, por la llamada en Meiggs "crisis de los 40", una posición dominante dentro de la arche ateniense. ${ }^{24}$ No es casual que en el momento de la Paz del 375 se ofrende una Victoria de oro, la primera del s. IV, ${ }^{25}$ al tesoro de Atenas de la acrópolis. En esa coyuntura se sitúa habitualmente el culto a la paz como memorial de la guerra. ${ }^{26} \mathrm{La}$ veneración a Eirene, así inaugurada (o realzada)

124 F 5- que aunque parece negar la paz, puede interpretarse también en el sentido contrario: BoswORTH 1990, 1-13) señalan los años 60, posteriores a Eurimedonte. Para otras noticias sobre la Paz: Isoc. Panegírico, 118120; D. 19 (Sobre la Embajada fraudulenta), 273; Paus. 1.8.2. Partidario de una fecha alta, tras Eurimedonte, conectándolo con la actividad de Calias en Susa en ese período como señala Heródoto (Hdt. 7.151): WALSH 1981, 31-63. Sin embargo el 450/449 es el punto de inflexión para el fin de hostilidades con los persas: MeIGGS 1972, 129-151, 598 y ss.; este autor postula la paz en el 450 y acepta la fecha de Diodoro, señalando que antes de la misma no hay paz (expedición de Pericles y Efialtes, la campaña en Egipto y la última, en Chipre, con Cimón): Meiggs 1972, 79, 93 y ss. En esta línea también: Fornara - SAMONS 1991, 87-91; Hornblower 1991, 179 y ss. A medio camino se encuentra la propuesta de BADIAN (1987; con nuevos argumentos: ID. 1993, 1-72) que supone que en ese momento hubo una renovación de la paz (realizada por el mismo Calias), esta vez efectiva. Ver reflexiones de Podlecki (1998, 67-69), quien defiende que lo más prudente es aceptar que no hubo paz formal pero sí un acuerdo tácito (contra este acuerdo también: ScHrader 1976, 203) entre Atenas y Persia, que coincide con el inicio del programa de construcciones de Pericles. Cf. Rung 2008, 31-33 (con más bibliografía). Para la política de construcciones: VALDÉs 2009.

20 Para asociación de Eirene con determinadas concepciones y para conceptos en torno a la paz (como el de prosperidad especialmente ligada a las cosechas, buen orden o philia, etc.): HANNAH 2014, 18 y ss. Ver también STAFFORD 2000, 183-202. Habría que añadir, sin duda, la victoria.

21 SERVADEI 2005, 135-141.

22 Parker 1996, 229-230; Hannah 2014, 14-15. Estatua de la diosa en el Pritaneo: Paus. 1.18.3.

23 Argumentos en Plácido 1996 (con fuentes y bibliografía anterior).

24 Plutarco (Cim. 13.6) dice que la paz de Calias fue el motivo por el que se erigió el altar de Eirene, lo que sin duda es erróneo (PARKer 1996, 230, n. 45), pero la causa tiene que ver con la potenciación de paz de Calias en el s. IV, que llevaría a identificar la nueva paz del 375 con la de Calias hasta entonces poco digna de consideración: PlÁcIDO 1996, 64-65. Para la idealización del imperio ateniense del s.V en torno a los intentos de recuperación del dominio del Egeo en el s. IV: Chambers 1975. Para la crisis de los 40 y las estrategias para afirmar el dominio de Atenas: ver infra nota 35.

25 PARKer 1996, 230; para victorias de oro: WoOdWARd 1937, 374, n ${ }^{\circ} 11$ y 17; ThOMPSON 1944, en especial 176-177. Licurgo reemplazó las victorias de oro de época periclea (recordado en decreto de 307/6 con honores póstumos a Licurgo); para Nikai de oro (al menos 8) almacenadas en el Partenón al inicio de la guerra del Peloponeso y luego dedicadas durante la guerra (en 426/5: $I G \mathrm{I}^{3}$ 468): Hurwit 1999, 230; ThOMPSON 1944, 174-176. Una Nike de bronce conmemoraba también victoria sobre espartanos en Esfacteria (425): Paus. 4.36.6. Dedicaciones de Nikai anteriores en la acrópolis: HuRwIT 1999, 230; cf. nota 13.

26 Ver notas 20 y 22. Cf. Isoc. 15.109-110; Philoch. FGH 328 F 151; Nepos Timotheus 2.2; Aeschin. 3.243. Se celebra su culto el 16 de hecatombeón coincidiendo con las Sinecias: PARKER 1996, 229-230; ID. 2005 , 478. Se asocia la paz con la posibilidad de prosperidad que, en el fondo, se liga a las probabilidades de recuperar el imperio con Timoteo: PLÁcIDo 1996, 61 y ss. 
de manera triunfante, difiere, en cualquier caso, de la paz-hesychia que se vincula a la inacción y a las políticas contrarias al imperialismo y a la guerra. Estas son propias de los poderosos de Atenas, los "pocos e ilustres", gravados con la eisphora en el s. $\mathrm{IV}^{27}$ que propiciaron, poco después, otra Paz, la del 371 auspiciada por Calístrato. ${ }^{28}$

En el s. V, la Paz de Calias, pero también la tregua previa del 451 y la posterior paz con Esparta del 445, se construyeron, ya en esa década, como una paz victoriosa, como muestra la proyección a inicios de los 40 de la construcción y del embellecimiento del lugar de culto de Nike con un nuevo templo. Varios autores han estudiado en detalle las fases constructivas del santuario ${ }^{29}$ y la teoría más plausible es que el proyecto del nuevo templo fuera retrasado por la obras de los propíleos de entrada a la acrópolis, ${ }^{30}$ de manera que no se llevó a cabo hasta el 427-424 aproximadamente, terminándose con la balaustrada ya bien avanzada la guerra del Peloponeso. ${ }^{31}$ En el templo se representan luchas entre griegos y contra persas en los frisos y, probablemente, escenas míticas de batallas contra gigantes y amazonas en los frontones. ${ }^{32}$

Aunque el templo no se edifica hasta los años 20, sí parece que se remonta a los años 40 un decreto que coincidiría con la decisión de construir el nuevo santuario

27 Contraria a la política de "los muchos y populares": Hell.Oxy. 1.3. Ar. Ec. 197-198. VALDÉs - ForNIS - PLÁCIDO 2007, especialmente 54.

28 Calístrato, favorable a la paz y a la concordia con Esparta en el 371: X. HG 6.3.1-17; TuPLIN 1993, 109 (revive la idea de hegemonía dual de Cimón); SeAley 1956, 192 y ss. Problemas financieros en relación con la paz del 371: Tuplin 1993, 162. Los autores del momento muestran que se buscan alternativas al imperio: X. Vect. en especial 1.1; Isoc. 8 (Sobre la Paz), sobre todo 19. Para la situación del momento: PLÁcido 1980, 65; VALDÉS 2016. Esta postura terminará por consolidarse en el momento de la guerra social, en los años 50 del s. IV, como puede verse en los Poroi de Jenofonte y Sobre la Paz de Isócrates. Para la ideología de la victoria en época helenística cf. Musti, ed., 2005.

29 MARK 1993; SHeAR 1999 (con crítica a Mark en cuanto a las fases cimonianas del santuario). Antes de la construcción del templo nuevo de Nike había un naiskos y un altar. MARK (1993) piensa que el naiskos es posterior al 450, de la época de Calícrates (también Holtzmann 2003, 154 y ss.), pero Shear (1999, 122124) ha demostrado que el altar y el naiskos deben de ser anteriores a la mitad del siglo (postula una fecha posterior a las guerras médicas). El altar de piedra calcárea sustituiría al bomos arcaico (ver nota 4), y fue reemplazado por otro de mármol como estipula el decreto del nuevo templo ( $\left.I G \mathrm{I}^{3} 35\right)$ : ver más abajo en el texto.

30 MeritT - WAdE-Gery 1963, 109-110: "The delay, of course, between the plan and its execution was due to a conflict of interest involving the south-west wing of the Propylaia and the precinct of Athena Nikè. This was finally resolved, as the preserved monuments testify, by a very considerable alteration in the original plan of the Propylaia. But when the Propylaia and the temple were first authorised the conflict was not foreseen. The decree, therefore, belongs earlier than 437 at the latest (the date at which the Propylaia were begun) and may belong much earlier" $y$ "the delay in construction was caused by delay in the start of the Propylaia and by a local topographical quarrel for which we still have the architectural evidence”. Ver también SHEAR 1999.

31 Simon (1985) piensa que la balaustrada es anterior a la última década del s. V y que representa un sacrificio de toros en las Oscoforias. Para JAMESON (1994) representaría un sacrificio preliminar a la batalla. Ver HURWIT 1999, 213-215, con bibliografía; este autor pone de relieve la similitud de la escultura de la Nike desabrochándose la sandalia con la imagen de Afrodita con el pie en una roca en el friso este del templo (ver nota siguiente). Para posible conexión del bastión con Afrodita en el arcaísmo: ver supra nota 6.

32 Simon 1985, 278; Hurwit 1999, 209 y ss. En general se cuestiona si las representaciones son genéricas o reproducen batallas concretas (las guerras médicas o combates concretos de la guerra del Peloponeso). Para frisos: PEMBerTon 1972 (asocia el friso sur a la batalla de Maratón y el friso norte, a la lucha contra corintios en Mégara en el 460). Este autor vincula el templo de Nike con el santuario jónico del Iliso, que cree destinado a Ártemis Agrótera; según él serían proyectados a la vez, pero mientras que el del Iliso se construyó antes, no fue así con el de Nike. Para esta similitud entre los dos templos que sitúa a inicios de la guerra del Peloponeso: PALAGIA 2005 (con discusión y bibliografía sobre posibles representaciones en los frisos). En el friso este se representa a Afrodita y Peitho (Sмiтh 2011, 56) y probablemente a Eirene como una de las Horas. Significativamente la construcción del templo coincide en fechas con la obra Cresfontes de Eurípides, en la que se elogia la paz en el fragmento 453 (COLLARD - CROPP 2008, 510-511); HANNAH 2014, 13. Para la reconstrucción del templo véase: www.nikeisnow.co.uk/index.php/athena-nike-temple. 
del bastión que, de hecho, es mencionado en la inscripción. El decreto versa, principalmente, sobre el establecimiento del sacerdocio femenino de Atenea Nike. ${ }^{33} \mathrm{Si}$ se acepta la teoría que defiende la fecha de la década de los 40 como la más probable para la inscripción, ${ }^{34}$ se percibe a través de este documento, como veremos también en otros indicios contemporáneos, la importancia que se concede en dicha década al culto de la Victoria: Atenas ha firmado una paz, un acuerdo o un cese de hostilidades, con los persas hacia el 449; previamente había cerrado una tregua con Esparta en el 451, tras la derrota de Egipto, y, poco después, sellará la Paz de "Treinta Años" con esta polis en el 446/5. ${ }^{35}$

Reproducimos el texto del decreto que consta en la tercera edición de Inscriptiones Graecae: ${ }^{36}$

In lapide superiore:

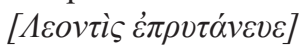

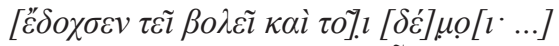

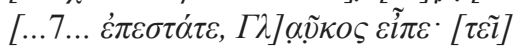

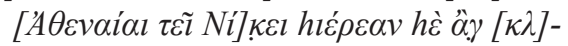

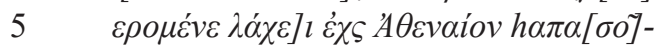

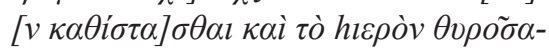

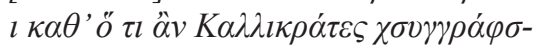

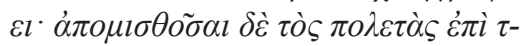



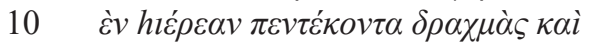

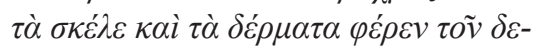

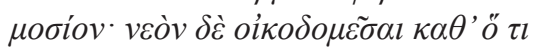

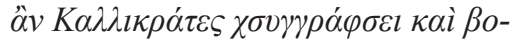

$\mu o ̀ v \lambda i \theta l v o v$ vacat

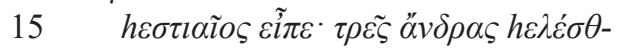

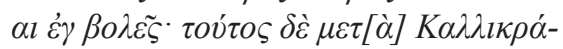

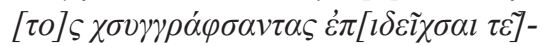

$33 I G \mathrm{I}^{3} 35\left(S E G \times\right.$ X $\left.5=I G \mathrm{I}^{2} 25\right)$ : ver texto y traducción infra. Inscripción situada tradicionalmente a inicios de los años 40 por cuestiones epigráficas, en concreto por la forma de letra sigma (con tres barras), ya que esta letra parece que desaparece hacia el 446: Papademetriou 1948-1949, 146-153; Merit - Wade-Gery 1958, 209, y 1963, 100 y ss.; Meiggs-Lewis 1988, 44. Esta teoría fue contestada por MatTingLy (1982 y 2000, seguido por GILL 2001) que fecha la inscripción en el momento de la construcción del templo de Nike (427-424). La cuestión epigráfica todavía no está resulta, puesto que se ha encontrado una inscripción que parece ser posterior a los años 40 con este tipo de letra sigma (decreto de Egesta: $I G \mathrm{I}^{3}$ 11; Mitchell 1998, 374; aunque no es seguro). Sin embargo hay otras consideraciones que dan coherencia a la fecha inicial (RHodes 2008): ver nota siguiente. MatTingly propuso inicialmente los años 30 (1961, 169-171), pero luego, tras la inscripción de Egesta (418), señaló una fecha próxima a la construcción del templo (427-424); para este autor la sacerdotisa fue elegida entonces (contemporáneamente a la construcción del templo) y sirvió a la diosa unos 15 años hasta su muerte (en torno a 410).

34 Hay otras consideraciones para los que prefieren la fecha alta, como las similitudes del trabajo de la piedra del decreto con la de la estatua de Atenea Promachos: Tracy 1984, 277-282; LougovayA-Ast 2006, $223-$ 224. Además SHEAR $(1999,124)$ argumenta que la estela fue desplazada y colocada en un bloque de mármol inacabado antes del final de las obras de los propíleos, es decir, antes del 432.

35 Tregua de 451: Th. 1.112.1; Plu. Cim. 18; Per. 10.4; Theopomp.Hist FGH 115 F 88. Paz de los Treinta Años del 446/5: Th. 1.115; D.S. 12.7. Cf. Sommerstein - BAYLiss 2013, 249 y ss. En los años 40 se produce lo que Meiggs llama la crisis de los 40 para el imperialismo ateniense (MeIGGs 1972, 161 y ss.), lo que lleva a desarrollar las armas de orden práctico e ideológico para mantener el control de la liga de Delos: cf. VALDÉs 2011.

36 Ver nota 33. 


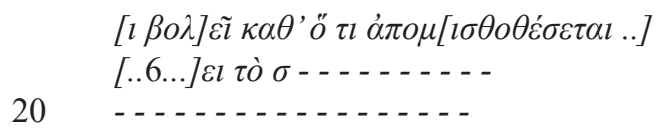

[Pritanía de Leontis] Dado por la Boule y el Demos.... presidía. Glaukos (?) propuso establecer como sacerdotisa de Atenea Nike a la que hubiera sido elegida por sorteo entre todas las atenienses y dotar de puertas el santuario según las especificaciones de Calícrates; y los poletai deben hacer el contrato en la pritanía de Leontis. La sacerdotisa recibirá cincuenta dracmas y las patas y la piel de los sacrificios públicos. Y el templo será construido según las especificaciones de Calícrates y un altar de mármol. Hestiaios propone que tres hombres serán elegidos por la Boule; y harán las especificaciones con Calícrates y deberán someter sus recomendaciones a la Boule de acuerdo con los contratos. ${ }^{37}$

El decreto es especialmente relevante desde el punto de vista religioso, pues es el primer testimonio de un sacerdocio, en este caso femenino, elegido de manera democrática, entre todas las atenienses. El auge del imperialismo coincide con el pleno desarrollo de la democracia radical. En el decreto se mencionan las prescripciones del arquitecto Calícrates, autor, con Ictino, del Partenón. Posiblemente proyectó también el templo de Nike en estos momentos, aunque, en cualquier caso, la inscripción estipula la colocación de puertas que cerraran el santuario (hieron: lín. 6) probablemente erigido en la fase precedente, en la que habría un naiskos, un altar y una estatua, ${ }^{38}$ previos a la construcción del nuevo templo (neos: lín. 12), planeado y citado en el texto y que se llevará a cabo en los años 20.

La inscripción menciona la instalación de la sacerdotisa de Atenea Nike, elegida entre las atenienses por sorteo, según la reconstrucción del texto avalada por la información proporcionada por el epitafio de Mirrina, la sacerdotisa de la diosa, ${ }^{39}$ que también reproducimos:

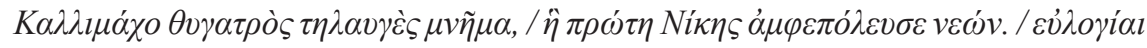

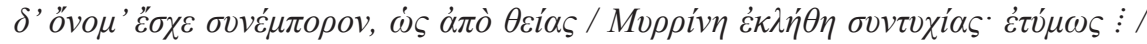

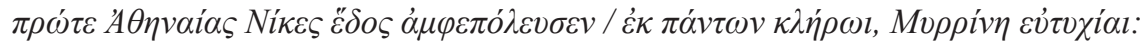

(He aquí) el luminoso monumento de la hija de Calímaco, la que fue la primera en servir en el templo (neos) de Nike. El nombre que recibió concuerda con esta alabanza puesto que, por suerte divina, se llamaba verdaderamente Mirrina. Fue la primera en servir en la sede (edos) de Atenea Nike, elegida entre todas (las atenienses) con un afortunado sorteo, Mirrina. ${ }^{40}$

37 Traducción propia. Otra restauración posible pero menos probable para la elección de la sacerdotisa en $I G \mathrm{I}^{2} 24$

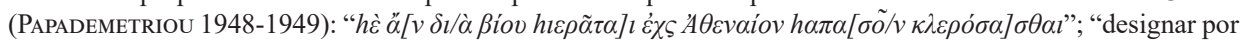
sorteo entre todas las atenienses a aquella que ejercerá el sacerdocio de por vida".

38 Para el estado de la cuestión de las construcciones del santuario: SHEAR 1999. MARK (1993) piensa que el naiskos es posterior al 450, de época de Calícrates (también Holtzmann 2003, 154 y ss.), pero Shear (1999, 122-124) ha demostrado que el altar y el naiskos deben de ser anteriores a la mitad del siglo (postula una fecha posterior a las guerras médicas). El altar de piedra caliza sustituiría al bomos arcaico que fue reemplazado por otro altar de mármol según el decreto $\left(I G \mathrm{I}^{3} 35\right)$.

39 SEG XII 80=IG $\mathrm{I}^{3}$ 1330. El epitafio fue encontrado a $3 \mathrm{~km}$ de Atenas, en Zographos. Cf. RaHn 1986; LougovaYAAst 2006. Papademetriou (1948-1949) piensa que Calímaco, el padre de Mirrina, es el mismo Calímaco arconte del 446, año del decreto según este autor.

40 Traducción propia. 
Muchos de los autores que lo han estudiado son de la opinión de que el sacerdocio se inaugura con ella y que el cargo lo tuvo por un muy largo periodo o de por vida. ${ }^{41}$ En realidad, como se observa en el texto, se trata de dos epitafios. En el primero se habla de neos (templo) mientras que en el siguiente se alude a que Mirrina fue la primera en servir en la sede (edos) de culto de la diosa. Probablemente el primero se refiere al templo nuevo edificado en los años 20 (al neos también del decreto comentado previamente), mientras que el segundo mencionaría la sede de culto (naiskos, altar y estatua) antes de la construcción del templo. El orden en el que aparecen no es por tanto cronológico y puede deberse, más bien, a la importancia de la función en relación con las construcciones de este espacio.

Parece que de esta misma Mirrina se conserva también un costoso lécito funerario que la representa junto a Hermes, ambos inscritos. ${ }^{42}$

El texto del decreto acropolitano señalado en primer lugar estipula, además de las puertas para el santuario (hieron) y de la creación de un templo nuevo y de un altar según las especificaciones de Calícrates, un salario para la sacerdotisa (50 dracmas) y provisiones para los sacrificios «demoteles» (las patas y la piel para la sacerdotisa). Sigue una enmienda de Hestiaios que asegura un procedimiento más democrático (por la implicación de la Boule). Parece que la piedra estuvo rematada con otra que recogería una primera inscripción, extremo éste ya sugerido por Dinsmoore y Meritt y reafirmado recientemente por Lambert y Blok. ${ }^{43}$ No conocemos el contenido del primer texto. En un artículo reciente Josine Blok sugería la posibilidad, bien documentada, de que esta primera piedra contuviera una inscripción con un decreto sobre la inauguración de sacrificios «demoteles» para la diosa Atenea Nike que iría seguido del decreto descrito ya mencionado $\left(I G \mathrm{I}^{3} 35\right) .{ }^{44}$ Probablemente la sacerdotisa de Atenea Nike fue elegida de por vida, como ya se ha señalado a partir de la información proporcionada por el epitafio. ${ }^{45}$

Existe un segundo decreto,${ }^{46}$ inscrito en la parte posterior del primero comentado, y fechado con seguridad en el 424. En él se confirma el salario de la sacerdotisa (50 dracmas) estipulado en el primer decreto, pagado por los colacretas en el mes de Targelion. El texto continúa con otras disposiciones no conservadas. Posiblemente este decreto se añadió al primero cuando se terminó de construir el templo, en los años 20 .

41 Se inaugura con ella: Meritt 1941, 310-311; MARK 1993; BloK 2014. Piensan que existe el sacerdocio con anterioridad: SchlaIFER 1940; JoRdAN 1979, 32-33; GARLAND 1984. Cuestión no resuelta: LougOvaYA-AST 2006, 213. De por vida: Aleshire 1994, 327, n. 12; Blok 2014, 116-118; cf. discusión en PARKer 1996, 126127 (con bibliografía).

$42 I G \mathrm{I}^{3}$ 1285. Encontrado en 1873 en la plaza Syntagma de Atenas. ClaIRmOnT (1979) cree que formaba parte del monumento funerario y que luego fue desplazado. Contra MARK $(1993,112)$ que postula la inexistencia de un vínculo entre los dos monumentos (igual que ConNelLy 2007, 228-228). Por su parte RAHN (1986) defiende que los dos monumentos hacen alusión a la misma mujer, Mirrina, la sacerdotisa de Atenea Nike, cuestión todavía abierta para Lougovaya-Ast 2006, 222, n. 32. Cf. HoltZMann 2003, 224.

43 Dinsmoore 1923; Meritt 1941; Shear 1999, 123, n. 209; Stephen Lambert en Blok 2014, 102, n. 8.

44 BLOK 2014. MERITT - WADE-GÉRY $(1963,110)$ sugirieron que el primer decreto trataba sobre los planes y la autorización para las obras de los propíleos, y que la inscripción conservada era sólo una enmienda del primer texto.

45 Ver notas 41 y 42.

$46 \quad I G \mathrm{I}^{3} 36\left(S E G \times 85=I G \mathrm{I}^{2} 25\right)$. 
En el primer decreto se utiliza el término athenaion (genitivo plural) para las mujeres de Atenas ${ }^{47}$ lo que es algo completamente excepcional. ${ }^{48}$ Esto podría indicar que la inscripción está efectivamente cercana a la fecha de la ley de Pericles del 451 que especifica que la ciudadanía pertenecía sólo a los descendientes de padre y madre astoi o atenienses. ${ }^{49}$ La sacerdotisa de Atenea Nike es la primera conocida, entre todos los sacerdocios, en ser elegida por sorteo entre el conjunto de las atenienses, es decir, democráticamente, aunque sin duda había una cierta "selección" y no todas se presentarían como candidatas. ${ }^{50}$ En estos años de política post efiáltica y periclea, hubo cambios importantes hacia la democratización. Tras el 457 los arcontes podían ser elegidos entre los zeugitai y no sólo entre las dos primeras clases ${ }^{51}$ Además probablemente en los años 50 Pericles inauguró la institución del misthos para ciertos oficios (bouleutai, soldados, heliastai). ${ }^{52}$

\section{La paz como victoria}

En este sentido el decreto se integra perfectamente en los años 40 propuestos por la mayoría de los epigrafistas. La atención al culto de Nike, la victoria, en esta década no solo se manifiesta en el decreto de la sacerdotisa de la diosa y en la planificación de la construcción de un templo nuevo, sino que se percibe asimismo de forma muy clara en la "omnipresencia" de las Nikai en el programa escultórico del Partenón iniciado en el 447, así como en la Victoria de la estatua crisoelefantina de Atenea Parthenos. ${ }^{53}$ El culto de Nike se asocia, sin duda, con la elaboración de la paz en esa década principalmente con los persas, pero quizás también con Esparta, como una Victoria. Esta idea se reencuentra después, durante la guerra del Peloponeso, como se ve por ejemplo en el pasaje de Orestes de Eurípides en el que, al final de la obra, Apolo dice:

47 PATterson 1987, 53.

48 LoRAux 1981, 128-129; ID. 1993, 217 y ss. La expresión más próxima la encontramos en Aristófanes: eugeneis gynaikes ton athenon (Ar. Th. 329-330).

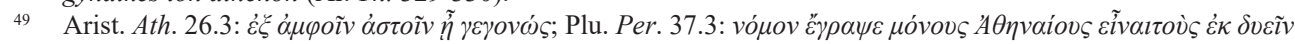

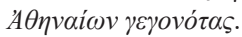

50 LAmbert $(2010,155-156)$ piensa en una limitación en este sentido. Sin duda, como testimonian tanto el epitafio como el lécito (ver notas 39 y 42), Mirrina era rica.

51 Arist. Ath. 26.2. Para zeugitai: VAldÉs - GALlego 2010.

52 Arist. Ath. 27.4; Plu. Per. 9. Introducción de misthophoria: PoDlecki 1998, 19, 54 (con bibliografía). Para el sentido del misthos que libera al demos de dependencias: Plácido 1997, 13 (este autor desarrolla el vínculo del misthos con el imperio de Atenas y el phoros).

53 Hurwit $(1999,230)$ resalta cómo la idea de la Victoria se vincula al Partenón y en general a la acrópolis en la época de las reconstrucciones de los años 40. Según este autor posiblemente la estatua de bronce de Atenea Prómacos portaba una Nike, como la tenía - con seguridad- la estatua de Atenea Parthenos crisoelefantina (HurwitT 1999, fig. 132). En el programa escultórico del Partenón aparece una Nike junto a Atenea en la metopa 4 (HuRwit 1999, fig. 137) preparando la corona de la diosa por su victoria contra los gigantes; Nike conduce el carro de la diosa en el pedimento oeste (fig. 145); es posible que esté como figura alada junto a Hera en el friso este (aunque podría ser Iris): fig. 150. Además había cuatro Nikai en las esquinas del techo del Partenón como si estuvieran trayendo noticias de victoria desde el Olimpo (Hurwit 1999, fig. 133). Los trabajos en el Partenón comienzan en 447/6: $I G \mathrm{I}^{3}$ 436. Para el inicio de las construcciones de la acrópolis véase la nota 55. Inciden en este idea: NeILS - Schultz 2012, 204. 
¡Emprended pues vuestro camino, venerando a la Paz como la más hermosa de las divinidades..." y el coro responde: ¡Oh muy venerable Victoria, ojalá domines el curso de mi vida y no dejes de coronarla! ${ }^{54}$

Esta afirmación de la paz como victoria se hace conveniente en un momento en el que Atenas tenía que afirmar su dominio sobre la liga de Delos, dominio que podía ponerse en entredicho como consecuencia del desastre de Egipto y del cese de hostilidades con los persas, así como por los acontecimientos de la guerra con Esparta de esos años. De hecho, en esa década no sólo se propone la reconstrucción de los templos destruidos por los persas ${ }^{55}$ como justificación del mantenimiento del tributo aliado, sino que se intenta un acercamiento a Delfos con la segunda guerra sagrada y cuando "falla" se recurre a la exégesis en Atenas para legitimar la reconstrucción de la acrópolis. ${ }^{56}$

En cualquier caso el templo de Nike no se construyó hasta el 427-424, finalizadas las obras también de los propíleos. En esas fechas Atenas está inmersa en la guerra del Peloponeso, en la guerra arquidámica (431-421). El templo de la diosa se termina precisamente en esa parte de la guerra, en momentos en los que se dedica una estatua a la diosa con el botín proveniente de los ambraciotas y de la insurrección de Corcira, entre otras acciones, como se ve por una inscripción del s. IV sobre la reparación de la estatua. ${ }^{57} \mathrm{El}$ año de la consagración del templo, el 424, es el año precisamente en el que se produjo un pacto con Darío, quizás una renovación de la Paz de Calias, por parte de Atenas, para asegurar su no intervención en el contexto de la guerra contra Esparta. $^{58}$

Antes del establecimiento de la sacerdotisa de Nike es posible que fuese el polemarco (encargado de los asuntos de la guerra) quien hiciese sacrificios ${ }^{59}$ públicos (¿ocasionales, no sistemáticos?) a Nike como diosa de la victoria en la guerra, del mismo modo que serán los estrategos los encargados del culto a Eirene ${ }^{60}$ En el caso de Nike parece lógico pensar que pudiera estar implicada en el culto también, con anterioridad al decreto comentado, ${ }^{61}$ la sacerdotisa de Atenea Polias ${ }^{62}$ que supervisaría

54 E. Or. 2682 y ss.; traducción de A. Martínez Díez (Editorial Clásicas). La obra se data en el 408; poco antes de esa fecha se habían producido las victorias atenienses de Cinosema (411) y Cícico (Th. 8.104-7; X. H.G. 1.1) lo que les lleva a obtener el control del Helesponto (X. H.G. 1.3) y conduce a Esparta a pedir la paz rechazada por la asamblea. Cf. Plácido 1996, 60.

55 Política de construcciones de Pericles criticada por la oposición: Plu. Per. 12.1. Para las construcciones y las fechas: MERITT - WADE-GERY 1962, 100-117 (especialmente 105 y 108, con mención del decreto de Estrasburgo); Hurwit 1999, 157 y ss.; Fornara - Samons 1991, 34, 73-74; AMELing 1985, 47-63; Hölscher 1998, $171-173$. Según Meiggs $(1972,515)$ el documento llamado "anónimo Argentinensis" o papiro de Estrasburgo podría fechar la decisión de utilizar el dinero de la acrópolis con fines públicos en las construcciones acropolitanas en el arcontado de Eutino (450-49); cf. PoDLECKI 1998, 167; VALDÉs 2009.

56 VALDÉS 2011.

57 LSG 35.16=IG II ${ }^{2}$ 403: del 350-320 a.C. Este es el momento en el que MatTingLY (ver nota 33) sitúa también la primera inscripción, que hace contemporánea de la segunda del 424 (ver nota 46). Según PARKER (1996, 244, n. 96) este decreto de reparación de estatua de Atenea Nike podría ser licurgeo.

58 And. 3.29; $I G \mathrm{I}^{3}$ 227. MeIGgs (1972) lo plantea como renovación de la paz de Calias, pero existen dudas de que sea tal. Cf. Thompson 1971; Blamire 1975; Badian 1993, 72-107; Rung 2008, 35.

59 Polemarco Arist. Ath. 58. Papel en el culto a Nike: BLOK 2014, 106.

60 Para este culto ver notas 20, 22 y 26.

${ }^{61}$ Para el decreto: ver nota 33. Para la polémica de si es elegida por primera vez una sacerdotisa del culto o si ya existía desde antes, así como para la discusión sobre si la sacerdotisa era elegida "de por vida" (como parece ser el caso a partir del epitafio), ver nota 41 .

62 También lo supone Simon 1985, 273. 
los ritos acropolitanos y se encargaba sin duda del sacrificio panatenaico, momento en el que se dedicaba a Nike la vaca más hermosa según un decreto del s. IV. ${ }^{63}$ Esta mujer además controlaría asimismo las ofrendas (privadas) en la acrópolis, como la realizada por Calímaco, el polemarco, a Nike comentada más arriba. ${ }^{64}$

La idea del vínculo de Nike, la victoria, con la Paz, Eirene, se puede observar también muy vívidamente en la obra de Aristófanes, Lisístrata, del $411 .{ }^{65}$ En ella las mujeres de Atenas buscan la paz con Esparta a través de una huelga de sexo, recluidas en la acrópolis, cerca del bastión de Nike. El tema, la guerra entre los sexos y la victoria femenina a través del poder de Cipris, junto con las referencias a Nike (v. 317), a las mujeres Kallonike (passim) y Nikodike (v. 321) o a las Nikai aladas del bastión, ${ }^{66}$ muestran que la paz femenina, en la víspera de la revolución del 411, se construye como una victoria frente a los hombres asociada con la tiranía y la toma de Cleómenes de Esparta de la acrópolis en el s. VI. ${ }^{67}$ En la obra se utilizan sugerentes imágenes y construcciones, vinculadas al tejido, de la paz asociada a las mujeres. Al final de la misma, la paz realizada por Cipris se alaba como el resultado de una victoria. $^{68}$

\section{Conclusiones}

Podemos concluir señalando que el acuerdo con los persas se elabora como una victoria sobre los mismos, concepto ensalzado a través de la proyección de un templo nuevo y del establecimiento de un sacerdocio democrático acorde con los tiempos, dedicados a Nike, pero también con la integración en la imaginería del Partenón de la Victoria. Además, esto lleva a Atenas a reivindicar como legítima (también a través de la política de construcciones) ${ }^{69}$ la continuidad del phoros y de la liga de Delos, que se ha convertido en un imperio. ${ }^{70}$

La asociación entre Nike y Eirene será recurrente en el imaginario ateniense, recibiendo distintas interpretaciones o elaboraciones, como la de la referida obra de Aristófanes, Lisístrata, donde se trata de una paz y de una victoria "femeninas", asociadas, entre otras imágenes, con la revolución oligárquica. También en el s. IV se retoma este vínculo entre Paz y Victoria en el momento de intento de reconstrucción del dominio ateniense en el Egeo, especialmente con Timoteo, y se escenifica, en este caso, con la inauguración del culto oficial de Eirene en Atenas y la consagración de una victoria de oro en la acrópolis. En definitiva, la paz se construye como una victoria y Nike, igual que Eirene, asegura la prosperidad ${ }^{71}$ de la ciudad en el imaginario ateniense.

\footnotetext{
$I G$ II $^{2}$ 334, lín. 20-21 (=LSCG 33 B 7-27); PARKER 2005, 265-266.

Ver nota 14.

Tema desarrollado en VALDÉs e.p. 1 (con bibliografía).

HURWIT 1999, 215.

Tiranía: En los vv. 617-18, con comentario de Sommerstern 1990. Cleómenes: v. 274.

Visiones de la paz: cf. VAldés e.p. 1. Paz y victoria Ar. Lys. 1289-1290. En este caso la paz es designada como hesychia, término de connotaciones oligárquicas: cf. VALDÉs - FORNIS - PLÁCIDO 2007.

69 VALDÉS 2009 y 2011.

70 PlÁcido 1996, 65 (Pericles consideraba que la paz era justificación suficiente para que los dineros de la liga fueran gastados en Atenas).

71 Relación de Eirene con Pluto y la prosperidad humana y natural: PlácIDo 1996; HanNA 2006, 16-18.
} 


\section{Referencias bibliográficas}

Aleshire, S. B. (1994): "The Demos and the Priests: The Selection of Sacred Officials at Athens from Cleisthenes to Augustus", [en] R. Osborne - S. Hornblower (eds.), Ritual, Finance, Politics: Athenian Democratic Accounts Presented to David Lewis, Oxford, 325-335.

Ameling, W. (1985): "Plutarch, Pericles 12-14”, Historia 34, 47-63.

BADIAN, E.

(1987): “The Peace of Callias", JHS 107, 1-39 (http://dx.doi.org/10.2307/630067).

(1993): From Plataea to Potidaea: Studies in the History and Historiography of the Pentecontaetia, Baltimore.

BESCHI, L. (1967-68): “Contributi di topografia ateniese”, ASAA 29-30, 511-536.

Blamire, A. (1975): “Epilycus' Negotiations with Persia”, Phoenix 29, 21-26 (http://dx.doi. org/10.2307/1087581).

BloK, J. (2014): “The priestess of Athena Nike. A new reading of IG I 35 and 36", Kernos 27, 99-126 (http://dx.doi.org/10.4000/kernos.2274).

Bosworth, A. B. (1990): "Plutarch, Callisthenes and the Peace of Callias", JHS 110, 1-13 (http://dx.doi.org/10.2307/631729).

Chambers, J. T. (1975): “The IV Century Athenian View of their V Century Empire”, PP 30, 177-191.

Clairmont, C. W. (1979): “The Lekythos of Myrrhine”, [en] G. Köpcke G. - M. Moore (eds.), Studies in Classical Art and Archaeology, New York, 103-110.

Collard, C. - Cropp, M. (EDS.), (2008): Euripides. Fragments: Aegeus-Meleager, Loeb Classical Library, Euripides VII, Cambridge, Mass.

Connelly, J. B. (2007): Portrait of a Priestess: Women and Ritual in Ancient Greece, Princeton.

Demargne, P. (1984): “Athena”, [en] The Lexicon Iconographicum Mythologiae Classicae (LIMC), vol. II. 1, Zürich-München, 955-1044.

Dinsmoor, W. B (1923): “The inscriptions of Athena Nike", AJA 27, 318-321 (http://dx.doi. org/10.2307/497850).

Fornara, Ch. W. - Samons II, L. J. (1991): Athens from Cleisthenes to Pericles, BerkeleyLos Angeles-Oxford.

GARLAND, R. (1984): "Religious Authority in Archaic and Classical Athens", ABSA 79, 75123 (http://dx.doi.org/10.1017/S0068245400019870).

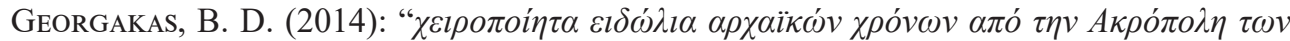

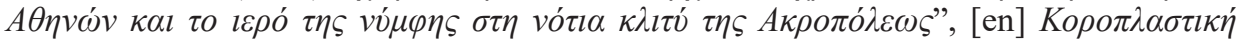

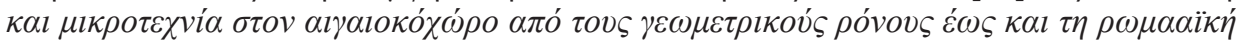
$\pi \varepsilon \rho i o \delta o "$, (Congreso Rodas nov. 2009), Athens, 69-80.

GiLl, D. W. (2001): "The Decision to Build the Temple of Athena Nike ("IG” I3 35)", Historia: Zeitschrift für Alte Geschichte 50/3, 257-278.

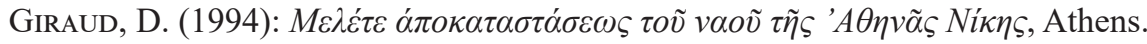

Goulaki-Voutira, A. - Moustaka, A. - Grote, U. (1992): “Nike”, The Lexicon Iconographicum Mythologiae Classicae (LIMC) VI.1, Zürich-München, 850-904.

Hanna, P. A. (2014): "Eirēnē: Ancient Greek Goddess and Concept of Peace", [en] T. Soghimen - V. A. Spencer (eds.), Visions of Peace. Asia and the West, Farnham-Surrey-Burlinton, 11-28. 
HöLSCHER, T. (1998): "Images and Political Identity: The Case of Athens", [en] D. Boedecker - K. A. Raaflaub (eds.), Democracy, Empire, and the Arts in Fifth-Century Athens, Cambridge (Mass.)-London, 153-183.

Holtzmann, B. (2003): L'Acropole d'Athènes: monuments, cultes et histoire du sanctuaire d'Athèna Polias, Paris.

Hornblower, S. (1991): A Commentary on Thucydides, volume I: books I-III, Oxford.

Hurwit, J. M. (1999): The Athenian Acropolis. History, Mythology, and Archaeology from the Neolithic Era to the Present, Cambridge.

Jameson, M. H. (1994): "The Ritual of Athena Nike Parapet", [en] R. Osborne - S. Hornblower (eds.), Ritual, Finance Politics, Oxford, 307-324.

Jordan, B. (1979): Servants of the Gods: a Study in the Religion, History and Literature of Fifth-century, Athens.

KeEsLIng, C. M. (2003): The votive statues of the Athenian Acropolis, Cambridge.

KüPPER, M. (1989): "Frühattische "Stempelidole" von Kiapha Thiti”, [en] Kiapha Thiti: Ergebnisse der Ausgrabungen III.2, Marburg, 17-29.

LAmbert, S. D. (2010): “A Polis and its Priests: Athenian Priesthoods before and after Pericles’ Citizenship Law”, Historia 59, 143-175.

Lonis, R. (1979): Guerre et religion en Grèce à l'époque classique, Paris.

LORAUX, N.

(1981): Les enfants d'Athènes. Idées athéniennes sur la citoyenneté et la division des sexes, Paris.

(1993): “Aristophane, les femmes d'Athènes et le théâtre", [en] O. Reverdin - B. Grange (eds.), Aristophane (=Entretiens sur l'Antiquité classique XXXVIII), Genève, 119-130.

Lougovaya-Ast, J. (2006): "Myrrhine, the first priestess of Athena Nike", Phoenix 60, 211 225.

Matheson, S. B. (1995): Polygnotos and Vase Painting in Classical Athens, Madison.

MARChETTI, P. (1993): "Recherches sur les mythes et la topographie d'Argos. I. Hermes et Aphrodite", $B C H$ 117, 211-223 (http://dx.doi.org/10.3406/bch.1993.1677). (1994): "Recherches sur les mythes et la topographie d'Argos", BCH 118, 131-160 (http:// dx.doi.org/10.3406/bch.1994.1663).

Mark, I. S. (1993): The Sanctuary of Athena Nike in Athens. Architectural Stages and Chronology (=Hesperia, suppl. 26), Princeton, NJ.

Mattingly, H. B.

(1961): "The Athenian Coinage Decree", Historia 10, 148-188.

(1982): "The Athena Nike Temple Reconsidered", AJA 86/3, 381-385 (http://dx.doi. org/10.2307/504427).

(2000): "The Athena Nike Dossier: IG I3 35/36 and 64 a-b", CQ 50/2, 604-606 (http:// dx.doi.org/10.1093/cq/50.2.604).

Meiggs, R. (1972): The Athenian Empire, Oxford.

MeIGGS, R. - LEwIS, D. M. (EDS.), (1988[1969]): A Selection of Greek Historical Inscriptions to the End of the Fifth Century B.C., Oxford.

MeISTER, K. (1982): Die Ungeschichtlichkeit des Kalliasfriedens und deren historische Folgen, Wiesbaden.

Meritt, B. D. (1941): “Notes on Attic Decrees", Hesperia 10/4, 301-337 (http://dx.doi. org/10.2307/146663). 
Meritt, B. D - Wade-Gery, H. T. (1963): “The Dating of Documents to the Mid-Fifth Century-II", JHS 83, 100-117 (http://dx.doi.org/10.2307/628456).

Mitchell, L. G. (1998): "Rev. of H.B. Mattingly, The Athenian Empire Restored: Epigraphic and Historical Studies (Oxford, 1996)", CR 48, 372-374.

Musti, D. (ED.), (2005): Ideologia, iconografia e feste della vittoria in età antica, Roma.

NeIls, J. - Shultz, P. (2012): "Erechtheus and the Apobates Race on the Parthenon Frieze (North XI-XII)", AJA 116/2, 195-208 (DOI: 10.3764/aja.116.2.0195).

Osborne, M. H. - Byrne, S. G. (1994): A Lexicon of Greek Personal Names, Vol. II, Attica. Oxford.

Palagia, O. (2005): "Interpretations of two Athenian friezes: the temple on the Ilissos and the temple of Athena Nike", [en] J. M. Barringer - J. M. Hurwit (eds.), Periklean Athens and its legacy, Austin, 177-192.

Papademetriou, J. (1948-1949): “Attika I”, ArchEph, 146-153.

PARKER, R.

(1996): Athenian Religion: A History, Oxford. (2005): Polytheism and Society at Athens, Oxford.

PARISI, V. (2014): “Terrecotte votive e pratiche rituali nell'Atene di VII secolo a.C.”, [en] L. M. Caliò - E. Lippolis - V. Parisi (cur.), Gli Ateniesi e il loro modello di città (Seminari di Storia e Archeologia greca I, Roma 25-26 giugno 2012), (=Thiasos Monographie 5), Roma, 23-35.

PAtTerson, C. (1987): "HAI ATTIKAI: The Other Athenians", [en] Rescuing Creusa: New Methodological Approaches to Women in Antiquity (=Helios new series 11), Texas, 4967.

Pemberton, E. G. (1972): "The East and West Friezes of the Temple of Athena Nike" AJA 76, 303-310 (http://dx.doi.org/10.2307/503923).

Pirenne-Delforge, V. (1994): L'Aphrodite grecque. Contribution à une étude de ses cultes et de sa personnalité dans le panthéon archaïque et classique (=Kernos, suppl. 4), Liège.

PLÁCIDO, D.

(1980): "La ley ática del 375/4 a.C. y la política ateniense", Memorias de Historia Antigua 4, 27-42.

(1996): "Las ambigüedades de la Paz. El culto de Irene en Atenas", [en] A. Pérez Jiménez - G. Cruz Andreoti (eds.), La religión como factor de integración y conflicto en el Mediterráneo, Madrid, p. 55-66.

(1997): La sociedad ateniense. La evolución social de Atenas durante la guerra del Peloponeso, Barcelona.

(1999): "La Grecia clásica", [en] AA.VV., El mundo clásico a través de sus textos. 1. Grecia, Madrid.

Podlecki, A. J. (1998): Perikles and his Circle, London-New York.

RAHN, P. J. (1986): "Funeral Memorials of the First Priestess ofAthena Nike", ABSA 81, 195 207 (https://doi.org/10.1017/S0068245400020153).

RAUBITSCHEK, A. E.

(1949): Dedications from the Athenian Akropolis. A Catalogue of the Inscriptions of the Sixth and Fifth Centuries B.C., Massachusetts.

(1940): "Two Monuments Erected after the Victory of Marathon", AJA 44/1, 53-59 (http://dx.doi.org/10.2307/499590).

Rhodes, P. J. (2008): "After the Three-Bar "Sigma" Controversy: The History of Athenian Imperialism”, CQ 58/2, 500-506 (http://dx.doi.org/10.1017/S000983880800058X). 
RitTer, S. (2001): “Athena in Archaic Corinth: the Creation of an Iconography”, [en] S. Deacy - A. Villing (eds.), Athena in the Classical World, Leiden-Boston-Köln, 143-162.

Rung, E. (2008): "War, Peace and Diplomacy in Graeco-Persian relations from the Sixth to Fourth Century BC", [en] Ph. De Souza - J. France (eds.), War and Peace in Ancient and Medieval History, Cambridge, 28-50.

Schlaifer, R. (1940): "Notes on Athenian Public Cults", HSCP 51, 233-260 (http://dx.doi. org/10.2307/310929).

Schrader, C. (1976): La Paz de Calias: testimonios e interpretación, Barcelona.

SEALEY, R. (1956): “Callistratos of Aphidna and his contemporaries”, Historia 5, 178-203.

SERVADEI, C. (2005): La figura di Theseus nella ceramica attica. Iconografia e iconologia del mito nell'Atene arcaica e classica, Bologna.

SHEAR, I. M. (1999): “The Western Approach to the Athenian Akropolis", JHS 119, 86-127 (http://dx.doi.org/10.2307/632313).

Shear, S. L. (2001): Polis and Panathenaia. The History and Development of Athena's Festival, Ph. D., Univiversity of Pennsylvania.

Simon, E (1985): "La decorazione architettonica del tempietto di Atena Nike sull'acropoli di Atene", MusPat 3, 271-288.

Smith, A. C. (2011): Polis and Personification in Classical Athenian Art, Leiden.

Sommerstein, A. H. (1990): The Comedies of Aristophanes, vol. 7: Lysistrata, Warminster.

Sommerstein, A. - Bayliss, J. (2013): Oath and State in Ancient Greece, Berlin.

Stafford, E. (2000): Worshipping Virtues. Personification and the Divine in Ancient Greece, Swansea-London.

Thompson, D. B. (1944): “The golden Nikai reconsidered”, Hesperia 13, 173-209 (http:// dx.doi.org/10.2307/147012).

Thompson, W. E. (1971): "The Athenian Treaties with Haliai and Dareios the Bastard", Klio $53,119-124$.

Tracy, S. V. (1984): "Hands in Fifth-Century B.C. Attic Inscriptions", [en] A. Boegehold et alii (eds.), Studies presented to Sterling Dow on his Eightieth Birthday (=GRBS Monograph 10), Durham NC, 277-282.

Travlos, J. (1971): Pictorial Dictionnary of Ancient Athens, London.

TuPLIN, C. (1993): The Failings of Empire, Stuttgart.

VALDÉS, M.

(2005): El papel de Afrodita en el alto arcaísmo. Política, guerra, matrimonio e iniciación, Messina.

(2009): "Decreto de Pritaneo y política délfica. Exégesis religiosa en la democracia de Pericles", [en] M. Campagno - J. Gallego - C. García Mac Gaw (eds.), Política y religión en el Mediterráneo antiguo. Egipto, Grecia y Roma, Buenos Aires, 195-228.

(2011): "Justificaciones religiosas del imperialismo ateniense en la época de la Pentecontecia”, [en] J. M. Cortés et alii (eds.), Grecia ante los Imperios. VReunión de historiadores del mundo griego, Sevilla, 141-154.

(2016): "Reformas en las cargas fiscales y sociedad ateniense en la primera mitad del s. IV: entre los problemas financieros y la renovación imperialista", [en] J. Pascual - B. Antela-Bernárdez - D. Gómez Castro (eds.), El mundo griego en el siglo IV a.C. Pervivencias, cambios y transformaciones, Madrid, 103-496.

(e.p. 1): "Poder, victoria y paz femeninas: el caso de Mirrina en Lisístrata de Aristófanes", [en] Poder y heterodoxia en el Imperio romano. Homenaje a María José Hidalgo de la Vega, Salamanca. 
(e.p. 2): “Atenea Nike, Panateneas y victoria sobre los gigantes: conflicto interno y paz en el Ática del s. VI a.C.”, Incidenza del Antico.

VAldés, M. - Fornis, C. - PlÁcIDo, D. (2007): "El sacrificio a las Semnai Theai en Atenas: autoridad y silencio (hesychia) en el Areópago y revitalización del culto en el s. IV", [en] S. Montero - $\mathrm{M}^{\mathrm{a}} \mathrm{C}$. Cardete (eds.), Religión y silencio. El silencio en las religiones antiguas, Madrid, 107-132.

VAldÉs, M. - GALlego, J. (2010): “Athenian zeugitai and the solonian census classes: new reflections and perspectives", Historia 59/3, 257-281.

WADE-GERY, H. T. (1958): Essays in Greek History, Oxford.

WALSH, J. (1981): "The Authenticity and the Dates of the Peace of Callias and the Congreso Decree", Chiron 11, 31-63.

Woodward, A. W. (1937): “The golden Nikai of Athena”, Arch. Eph., 159-170. 